\title{
PERBANDINGAN KADAR FLAVONOID SERBUK INSTAN KUNYIT PUTIH (CURCUMA ZEDOARIA ROSC.) YANG BEREDAR DI PASARAN DENGAN METODE SPEKTROFOTOMETRI UV-VIS Trirakhma Sofihidayati, Sri Wardatun dan Alvia Suraya
}

Universitas Pakuan Bogor, Indonesia

E-mail: trirakhma@gmail.com, sriwardatun14@gmail.com dan alviasuraya@gmail.com

\section{Diterima:}

26 November

2021

Direvisi:

Disetujui:

\section{Abstrak}

Latar belakang: Minuman herbal siap saji merupakan produk bahan minuman berbentuk serbuk atau granula yang biasa dibuat dari gula dan rempah-rempah yang dicampur menjadi satu dengan atau tanpa penambahan bahan makanan lain. Metode: Penelitian ini bertujuan untuk menentukan perbandingan kadar Flavonoid dari berbagai serbuk instan kunyit putih yang beredar di pasaran dengan merek (I), (II), (III), (IV) dan (V) dengan 2 Batch yang berbeda pada setiap merek dilakukan menggunakan metode spektrofotometri UV-Vis. Hasil: Hasil kadar flavonoid dari serbuk instan kunyit putih berbagai merek yang beredar di pasaran yaitu kadar flavonoid yang paling tinggi terdapat pada sampel merek (I)pada (batch A) dengan kadar sebanyak 5,366\% dan (II) pada (batch B) dengan kadar sebanyak 5,423\%. Kesimpulan: kadar flavonoid terendah terdapat pada merek (IV) 2,851\% (batch B) dan 3,024\% (batch A).

Kata kunci: Serbuk Instan Kunyit Putih, Flavonoid, Spektrofotometri UV-Vis

\begin{abstract}
Background: Ready-to-eat herbal drinks are beverage products in the form of powders or granules which are usually made from sugar and spices mixed together with or without the addition of other food ingredients. Methods: This study aims to determine the ratio of flavonoid levels of various white turmeric instant powders circulating in the market under the brands (I), (II), (III), $(I V)$ and $(V)$ with 2 different batches of each brand using the method. UV-Vis spectrophotometry. Results: The results of flavonoid levels from various brands of white turmeric instant powder circulating in the market, namely the highest flavonoid levels were found in brand samples (I) in (batch A) with levels of $5.366 \%$ and (II) in (batch B) with levels of 5,423. \%. Conclusion: the lowest flavonoid content was found in brand (IV) $2.851 \%$ (batch B) and $3.024 \%$ (batch A).
\end{abstract}

Keywords: Instan White Tumeric Powder, Flavonoid, spectrophotometer UV-Vis 


\section{Pendahuluan}

Rempah yang dikenal luas di Indonesia adalah tanaman kunyit-kunyitan yang merupakan tanaman daerah tropis yang sangat berguna. Rimpang dari berbagai jenis tanaman digunakan sebagai rempah-rempah, obat-obatan, bahan kosmetik dan pewarna makanan (Sunarno \& Anggia, 2019). Salah satu jenis suku kunyit-kunyitan adalah kunyit putih yang rimpangnya berbentuk spesifik dan dapat dibedakan dari rimpang lainnya (Andia Bae, 2015). Berdasarkan penelitian pengalaman (empiris) kunyit putih memiliki manfaat menyembuhkan berbagai macam penyakit yaitu sebagai antioksidan, antikanker, asma, hepatitis, menurunkan kadar, kolesterol dan trigliserida darah, TBC, sinusitis (Fitriasari, 2015). Komponen utama dalam rimpang kunyit putih adalah kurkuminoid, flavonoid, polifenol dan minyak atsiri. Kunyit putih berkhasiat menetralkan racun, menghilangkan rasa nyeri sendi, menurunkan kadar kolesterol, antibakteri dan sebagai antioksidan alami penangkal senyawa radikal bebas yang berbahaya (Utami, Puspaningtyas, \& Gz, 2013).

Konsumsi minuman herbal khususnya herbal siap saji akan mempermudah dalam mengkonsumsi minuman herbal yang mudah dibawa. Minuman herbal siap saji merupakan produk bahan minuman berbentuk serbuk atau granula yang biasa dibuat dari gula dan rempah-rempah yang dicampur menjadi satu dengan atau tanpa penambahan bahan makanan lain (Kurniawan, 2018). Serbuk granul yang beredar di pasaran berasal dari daerah yang berbeda sehingga dimungkinkan bahan baku juga berasal dari daerah berbeda (Tarigan, Panjaitan, \& Tampubolon, 2015). Daerah penghasil bahan baku dapat mempengaruhi kadar metabolit dalam suatu tanaman (Efendi \& Harta, 2014). Berdasarkan hal diatas maka penelitian ini dilakukan untuk Penelitian ini akan menentukan kadar flavonoid dari beberapa serbuk instan kunyit putih yang beredar di pasaran. Kadar flavonoid ditentukan dengan spektrofotometri UV-Vis menggunakan pereaksi alumunium klorida. Metode ini digunakan karena alumunium klorida ( $\mathrm{AlCl} 3)$ sebagai pereaksi pengompleks dengan gugus orto-dihidroksi dan menimbulkan pergeseran khas menuju pita panjang gelombang tinggi yang berguna pada analisis beberapa golongan flavonoid (Frida, 2018).

\section{Metode Penelitian}

Penelitian ini akan dilaksanakan pada bulan Mei - Juli 2019 bertempat di Laboratorium Farmasi, Fakultas Matematika dan Ilmu Pengetahuan Alam Universitas Pakuan. Alat yang digunakan dalam penelitian ini yaitu alat-alat gelas, timbangan analitik digital, spektrofotomet. Bahan yang digunakan dalam penelitian ini adalah serbuk instan kunyit putih yang beredar dipasaran, Alumunium Klorida 10\%, air suling, Bouchardat LP, Etanol, Metanol, serbuk Kuersetin, Natrium Asetat 1 M, Asam Klorida 2N, Natrium Klorida 10\%, perekasi Mayer LP, serbuk Magnesium, serbuk Asam Borat, serbuk Asam Oksalat.

\section{Hasil dan Pembahasan}

Serbuk instan kunyit putih yang digunakan dalam penelitian ini diperoleh dari beberapa pedagang seperti di pasar dan toko online. Terdapat 5 merek serbuk instan kunyit putih yang digunakan dalam penelitian ini yaitu merek (I), merek (II), merek (III), merek (IV), dan merek (V). Dari setiap merek dilakukan pengambilan 2 sampel yang berbeda kode produksi (batch) untuk dilihat perbandingan kadar flavonoid dalam serbuk 
instan kunyit putih. Karakter dari serbuk instan kunyit putih yaitu memiliki warna serbuk yang putih, berbau khas dan rasa pahit. Alasan menggunakan sampel dengan merek di atas adalah dari segi harga murah dan dari daerah yang masih dapat dijangkau dengan mudah.

\section{a. Penetapan Kadar Air Serbuk Instan Kuyit Putih}

Suatu bahan perlu diketahui kadar air untuk melihat seberapa banyak air yang terkandung di dalam bahan dan ketahanannya dalam penyimpanan. Semakin kecil kadar air yang terdapat dalam suatu bahan maka akan semakin kecil resiko kerusakan oleh mikroorganisme. Hasil penetapan kadar air dapat dilihat pada gambar 2.

\begin{tabular}{ccc}
\hline Sampel & \multicolumn{2}{c}{ Rata-rata Kadar Air \% } \\
\cline { 2 - 3 } & Batch A & Batch B \\
\hline I & $5,79 \%$ & $4,94 \%$ \\
\hline II & $5,76 \%$ & $6,16 \%$ \\
\hline III & $7,87 \%$ & $7,64 \%$ \\
\hline IV & $7,38 \%$ & $6,88 \%$ \\
\hline V & $9,70 \%$ & $8,77 \%$ \\
\hline
\end{tabular}

Gambar 1. Kadar Air Serbuk Instan Kunyit Putih

\section{b. Hasil Penetapan Kadar Abu Serbuk InstanKunyit Putih}

Pemeriksaan ini bertujuan untuk mengetahui pencemaran bahan anorganik dan mineral pada serbuk instan kunyit putih. Prinsip penetapan kadar abu yaitu bahan dipanaskan pada temepratur tertentu dimana senyawa organik dan turunannya terdestruksi kemudian menguap, sehingga yang tertinggal hanya senyawa anorganik dan mineral (Depkes RI, 2000).

\begin{tabular}{ccc}
\hline \multirow{2}{*}{ Sampel } & \multicolumn{2}{c}{ Rata-rata Kadar Abu \% } \\
\cline { 2 - 3 } & Batch A & Batch B \\
\hline I & $6,53 \%$ & $7,38 \%$ \\
\hline II & $5,75 \%$ & $7,36 \%$ \\
\hline III & $6,23 \%$ & $7,24 \%$ \\
\hline IV & $6,72 \%$ & $7,11 \%$ \\
\hline V & $7,18 \%$ & $6,69 \%$ \\
\hline
\end{tabular}

Gambar 2. Kadar Abu serbuk instan kunyit putih

Semua merek serbuk instan kunyit putih (Curcuma zedoaria Rosc.) telah memenuhi persyaratan kadar abu. Pesyaratan kadar abu kunyit tidak boleh lebih dari 9\% (Khusna, 2019). Serbuk instan kunyit putih dari berbagai merek (I, II, III, IV dan V) mengandung senyawa metabolit sekunder yaitu alkaloid, flavonoid, saponin dan tanin Hasil ini telah sesuai dengan kunyit putih mengandung senyawa alkaloid, flavonoid, tanin dan saponin (Dewi, 2020).

Pada penelitian ini penentuan panjang gelombang maksimum dilakukan dengan menggunakan spektrofotometer UV-Vis pada daerah panjnag gelombang 420-440 nm dan konsentrasi yang digunakan adalah 100 ppm sehingga diperoleh panjang gelombang 
maksimum $433 \mathrm{~nm}$, hasil tersebut tidak jauh berbeda dengan penelitian sebelumnya, dimana sebelumnya menunjukkan bahwa panjang gelombang yang didapat yaitu $431 \mathrm{~nm}$ (Ahmad, Juwita, \& Ratulangi, 2015). Tujuan penentuan panjang gelombang maksimum yaitu agar mengetahui daerah serapan yang dapat dihasilkan berupa nilai absorbansi dari larutan baku kuersetin yang diukur serapannya menggunakan alat spektrofotometer UVVis pada rentang panjang gelombang 420-440 nm (Fangohoy, Sudewi, \& Yudistira, 2019).

Penentuan waktu inkubasi optimum dilakukan untuk mengetahui waktu penyimpanan yang memberikan serapan stabil yang dibutuhkan oleh suatu zat agar bereaksi secara maksimal (Saptari, Triastinurmiatiningsih, Sari, \& Sayyidah, 2019). Pada penelitian ini, waktu inkubasi dilakukan pada beberapa waktu yaitu 5, 10, 15, 20 dan 30 menit. Hasil uji menunjukkan waktu absorbansi optimum yang didapat adalah pada menit ke 20, hasil tersebut sesuai dengan hasil penelitian sebelumnya, dimana hasil penelitian sebelumnya menunjukkan bahwa waktu inkubasi optimum yang didapat selama 20 menit (Andriyanto, Slamet, \& Ariawan, 2013).

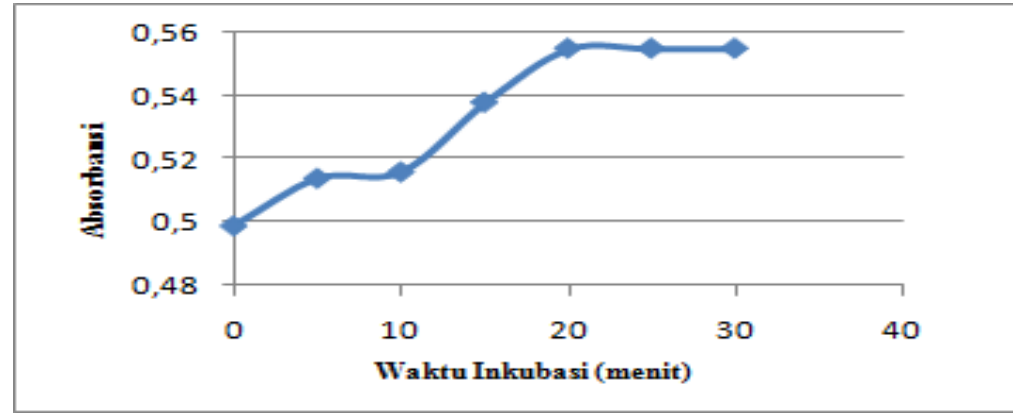

Gambar 3. Waktu Inkubasi

Penentuan kadar flavonoid pada berbagai serbuk instan kunyit putih dapat didasarkan pada nilai absorbansinya. Data larutan standar digunakan untuk membuat persamaan regresi. Kurva kalibrasi dibuat untuk menentukan kadar senyawa yang belum diketahui konsentrasinya.

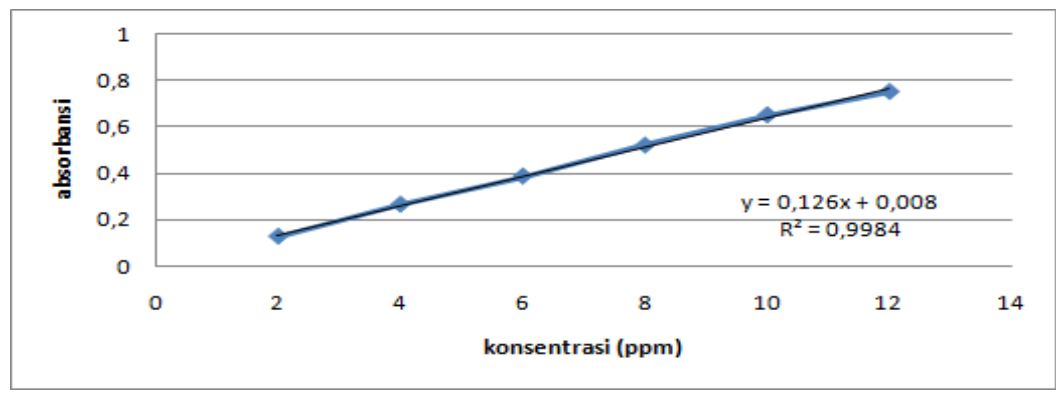

Gambar 4. Konsentrasi (ppm)

dapat dilihat kurva menghasilkan persamaan $\quad y=0,126 x+0,008$ dimana nilai $\mathrm{x}$ menunjukkan kadar serbuk instan kunyit putih, jika absorban serbuk instan kunyit putih dimasukkan sebagai nilai y maka dapat dihitung nilai x sebagai kadar (ppm). Kurva menghasilkan nilai R2 $=0,9984$, nilai ini menunjukkan hampir mendekati linearitas 1 , maka dapat dikatakan bahwa absorban merupakan fungsi yang nilainya berbanding lurus dengan konsentrasi dan mengikuti persamaan regresi linear. 
Penetepan kadar flavonoid menggunakan metode spektrofometri UV-Vis. Metode analisis flavonoid yang digunakan dalam penelitian ini adalah metode alumunium klorida dengan standar yang digunakan adalah kuersetin. Pereaksi $\mathrm{AlCl} 3$ yang digunakan bertujuan untuk mendeteksi gugus hidroksil dan keton yang berdekatan dengan gugus orto-hidroksi, karena antara $\mathrm{AlCl} 3$ dengan kedua gugus tersebut akan terjadi reaksi pembentukan senyawa kompleks. Persamaan regresi didapatkan dari grafik antara konsentrasi dan absorbansi larutan standar. Persamaan regresi yang didapatkan $\mathrm{y}=$ 0,126x + sama tinggi. 0,008 dengan nilai R2 $=0,9984$ pada kuersetin. Penetapan kadar flavonoid total diujikan pada beberapa merek serbuk instan kunyit putih yang beredar di pasaran untuk mengetahui perbedaan kadar kandungannya pada masing- masing sampel.

Kadar flavonoid paling tinggi terdapat pada sampel (V) serbuk instan kunyit putih batch A. Sedangkan kadar flavonoid yang paling tinggi terdapat pada sampel (II) serbuk instan kunyit putih batch B. Kadar flavonoid yang paling rendah terdapat pada sampel (IV) baik pada batch A maupun batch B. Hal tersebut dapat disebabkan dari proses pembuatan sediaan yang berbeda dan tempat sumber/tumbuh dapat berpengaruh seperti kondisi lingkungan, suhu, sinar ultraviolet, hara dan ketersediaan air dan kadar CO2 pada atmosfer (Rohaeti, 2011).

Berdasarkan hasil uji ANOVA diperoleh nilai Sig Sig $=0.000<\alpha=0.05$, dengan demikian dapat diperoleh kesimpulan bahwa ada perbedaan sampel serbuk instan kunyit putih yang beredar di pasaran pada batch A dan batch B terhadap kadar flavanoid yang dihasilkan. Untuk mengetahui pasangan sampel apa saja yang memberikan kadar flavanoid yang sama maupun yang berbeda maka dilakukan uji lanjut dengan metode Duncan (Rahmawati, Hidayatullah, \& Suprayatmi, 2017). Berdasarkan hasil uji lanjut dengan metode Duncan pada batch A dan batch B diperoleh bahwa sampel serbuk instan kunyit putih merek (II) dengan merek (V) memberikan kadar flavanoid tidak jauh berbeda. Sementara itu, merek (IV), (I), dan (III) memberikan kadar flavanoid yang berbeda dengan merek-merek serbuk instan kunyit putih yang lainnya. Berdasarkan hasil uji lanjut Duncan pada Batch A dan Batch B dapat diperoleh kesimpulan bahwa merek (II) dan merek (V) memberikan kadar flavanoid.

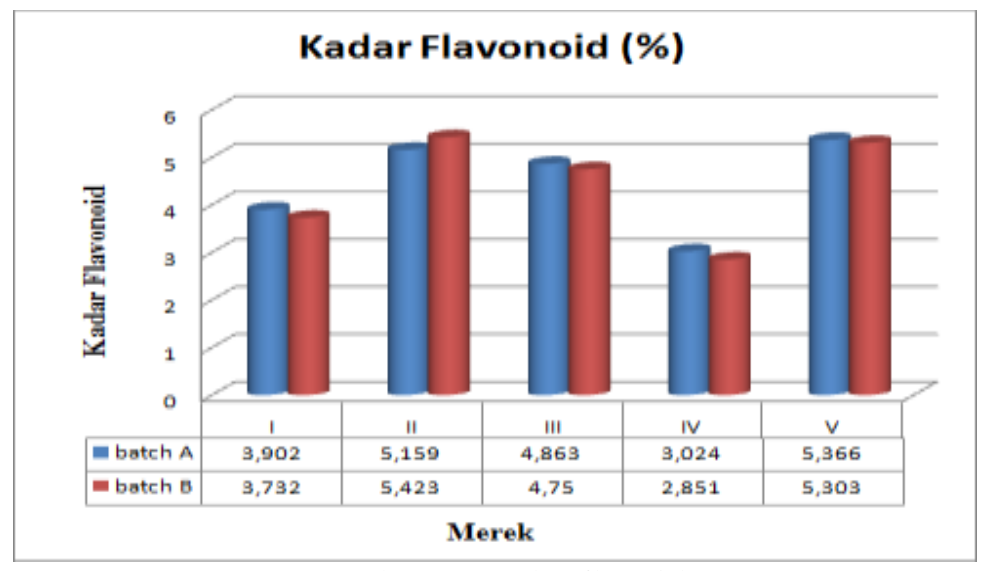

Gambar 5. Kadar flavoid

\section{Kesimpulan}

Berdasarkan hasil penelitian yang telah dilakukan dapat disimpulkan bahwa serbuk instan kunyit putih yang mengandung kadar flavonoid paling tinggi adalah merek (V) dengan kadar sebesar 5,366 \% (batch A) dan merek (II) dengan kadar sebesar 5,423\% (Batch B). Sedangkan serbuk instan kunyit putih yang mengandung kadar flavonoid 
paling rendah adalah dari merek (IV) dengan perolehan \% kadar sebesar 3,024\% (Batch A) dan $2,851 \%$ (Batch B).

\section{Bibliografi.}

Ahmad, Aktsar Roskiana, Juwita, Juwita, \& Ratulangi, Siti Afrianty Daniya. (2015). Penetapan kadar fenolik dan flavonoid total ekstrak metanol buah dan daun patikala (Etlingera elatior (Jack) RM SM). Pharmaceutical Sciences \& Research, 2(1), 1.

Andia Bae, Sandyi. (2015). Penentuan Kadar Senyawa Flavonoid dan Fenolik Ekstrak Rimpang Kunyit Putih (Curcuma zedoaria Rosc.). Makassar: UIN Alauddin Makassar.

Andriyanto, Wawan, Slamet, Bejo, \& Ariawan, I. Made Dharma Jaya. (2013). Perkembangan Embrio Dan Rasio Penetasan Telur Ikan Kerapu Raja Sunu (Plectropoma Laevis) Pada Suhu Media Berbeda Embryonic Development And Hatching Eggs Ratio Of Blacksaddled Coral Grouper (Plectropoma laevis) AT Different Temperature Media. Jurnal Ilmu Dan Teknologi Kelautan Tropis, 5(1), 193.

Dewi, Nugrahitasari. (2020). Standardisasi Parameter Spesifik Ekstrak Rimpang Kunyit Putih (Curcuma Zedoaria) Dari Dua Tempat Tumbuh. Semarang: Universitas Wahid Hasyim.

Efendi, Zul, \& Harta, Linda. (2014). Kandungan nutrisi hasil fermentasi kulit kopi (Studi kasus desa air meles bawah kecamatan curup timur). Jurnal BPTP Bengkulu, Bengkulu.

Fangohoy, Juliandro, Sudewi, Sri, \& Yudistira, Adithya. (2019). Prediksi Model Penetapan Kadar Flavonoid Total Pada Ekstrak Abelmoschus manihot L. Menggunakan Spektroskopi Ir Yang Dikombinasikan Dengan Kemometrik. Pharmacon, 8(2), 480-487.

Fitriasari, Ulfah. (2015). Uji Efektivitas Ekstrak Metanol Rimpang Kunyit Putih (Curcuma Zedoaria (Berg) Roscoe) Terhadap Penurunan Pada Kadar Kolesterol Pada Mencit. Makassar: UIN Alauddin Makassar.

Frida, Frihandini. (2018). Perbandingan Kadar Flavonoid Total Ekstrak Etanol Daun Jamblang (Syzgium cumini (L.) Skeels) Pada Dua Tempat Tumbuh. Semarang: Universitas Wahid Hasyim Semarang.

Khusna, Umi Nihayatul. (2019). Studi etnobotani pemanfaatan suku zingiberaceae di Desa Colo Kecamatan Dawe Kabupaten Kudus Provinsi Jawa Tengah. Semarang: UIN Walisongo.

Kurniawan, Arief Rakhman. (2018). Dasar-Dasar Marketing: Segala Hal Tentang Marketing dan Sales. Anak Hebat Indonesia.

Rahmawati, Siti Irma, Hidayatullah, Syarif, \& Suprayatmi, Mira. (2017). Ekstraksi Fikosianin Dari Spirulina Plantesis Sebagai Biopigmen dan Antioksidan. Jurnal Pertanian, 8(1), 36-45.

Rohaeti, Eti. (2011). Prediksi kadar flavonoid total tempuyung (Sonchus arvensis L.) menggunakan kombinasi spektroskopi IR dengan regresi kuadrat terkecil parsial.

Saptari, Tri, Triastinurmiatiningsih, Triastinurmiatiningsih, Sari, Bina Lohita, \& Sayyidah, Indah Nur. (2019). (Padina australis). FITOFARMAKA: Jurnal Ilmiah Farmasi, 9(1), 1-8.

Sunarno, Sunarno, \& Anggia, Putri. (2019). Pemberdayaan Masyarakat Ngepas Kidul 
melalui Budi Daya Jahe. Prosiding Seminar Nasional Program Pengabdian Masyarakat. Tarigan, Adil Makmur, Panjaitan, Rosnike Merly, \& Tampubolon, Antetti. (2015). Isolasi Selulosa Dari Tongkol Jagung Sebagai Bahan Pengisi Pembuatan Tablet Klorfeniramin Maleat Cetak Langsung. Jurnal Ilmiah Pannmed (Pharmacist, Analyst, Nurse, Nutrition, Midwivery, Environment, Dentist), 10(1), 1-10.

Utami, Prapti, Puspaningtyas, Desty Ervira, \& Gz, S. (2013). The miracle of herbs. AgroMedia.

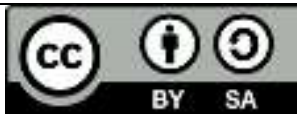

This work is licensed under a Creative Commons Attribution-ShareAlike 4.0 International License. 